\title{
Native and non-native sentence comprehension in the presence of a competing talker
}

\author{
Valdés-Laribi, Huarda; Wendt, Dorothea; Cooke, Martin; MacDonald, Ewen; Mattys, Sven
}

Publication date:

2014

Document Version

Publisher's PDF, also known as Version of record

Link back to DTU Orbit

Citation $(A P A)$ :

Valdés-Laribi, H., Wendt, D., Cooke, M., MacDonald, E., \& Mattys, S. (2014). Native and non-native sentence comprehension in the presence of a competing talker. Poster session presented at 4th Annual Conference of the British Society of Audiology, Keele, United Kingdom.

\section{General rights}

Copyright and moral rights for the publications made accessible in the public portal are retained by the authors and/or other copyright owners and it is a condition of accessing publications that users recognise and abide by the legal requirements associated with these rights.

- Users may download and print one copy of any publication from the public portal for the purpose of private study or research.

- You may not further distribute the material or use it for any profit-making activity or commercial gain

- You may freely distribute the URL identifying the publication in the public portal 


\section{Native and non-native sentence comprehension in the presence of a competing talker}

\section{Huarda Valdés-Laribi ${ }^{1}$, Dorothea Wendt ${ }^{2}$, Martin Cooke ${ }^{3}$, Ewen MacDonald ${ }^{2}$, Sven Mattys ${ }^{1}$}

1 The University of York, ${ }^{2}$ Technical University of Denmark, ${ }^{3}$ University of the Basque Country

\section{Introduction}

$>$ In everyday environments, we often have to attend to one person (target speech) while ignoring another (competing speech). Competing speech can mask the target through energetic masking (EM, acoustic degradation at the periphery) and informational interference (higher-order, cognitive aspects of masking).

$>$ Many studies have investigated the effect of masking on sound and word identification. Fewer have investigated its effect on sentence comprehension.

- This study aims to test whether informational interference is especially detrimental (relative to energetic masking) to sentence comprehension, particularly to sentences requiring a greater amount of processing resources, such as syntactically complex sentences, as in the examples below.

Less syntactic complexity, less processing resources More syntacicic complexity, more processing resou Subject relative: Show the girl who is holding the boy. Object relative: Show the girl who the boy is holding.

\section{Research questions}

Is a competing talker (energetic masking + informational interference) more detrimenta sentence comprehension than energetic masking alone?

Yes: Koelewijn et al. (2012), Brungart et al. (2001), Brungart et al. (2013)

$>$ No: Dirks and Bower (1969), Hygge et al. (1992)

2) Does the syntactic complexity effect (Obj Rel more difficult than Subj Rel) generalise cross types of masks and language background?

> Yes: e.g. Just and Carpenter (1992) for unmasked sentence comprehension in L1, Carroll and $L 1$, Izumi (2003) for greater difficulty in relative clause comprehension in a second language. Is a competing talker more detrimental to comprehension of more complex target sentences (Obj Rel)?

$>$ Yes: if the
complexity

$>\mathrm{No}$ : if the processing resources involved in informational interference and syntactic complexity are different, or if informational interference does not increase processing resources.

4) Is a competing talker more detrimental to sentence comprehension for L2 listeners? $>$ Yes: L2 listeners expend more processing resources to recognise and understand speech (Lecumberri et al., 2010). If informational interference requires more processing resources,
effect of a competing talker will be even greater for L2 listeners, in particular for complex

language, listeners can show release from masking (e.g. (2006)

\section{Method}

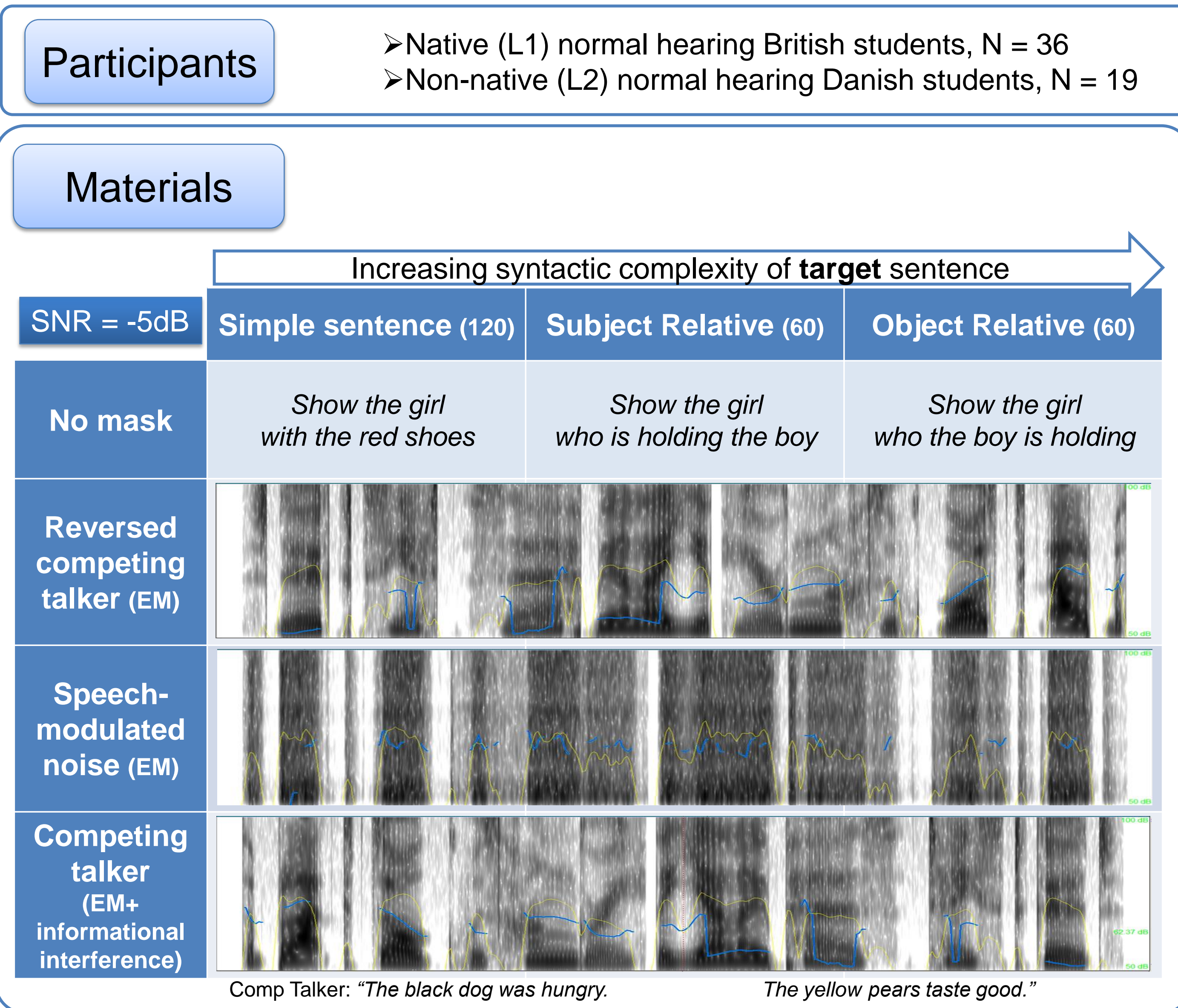

Task: Speeded picture selection
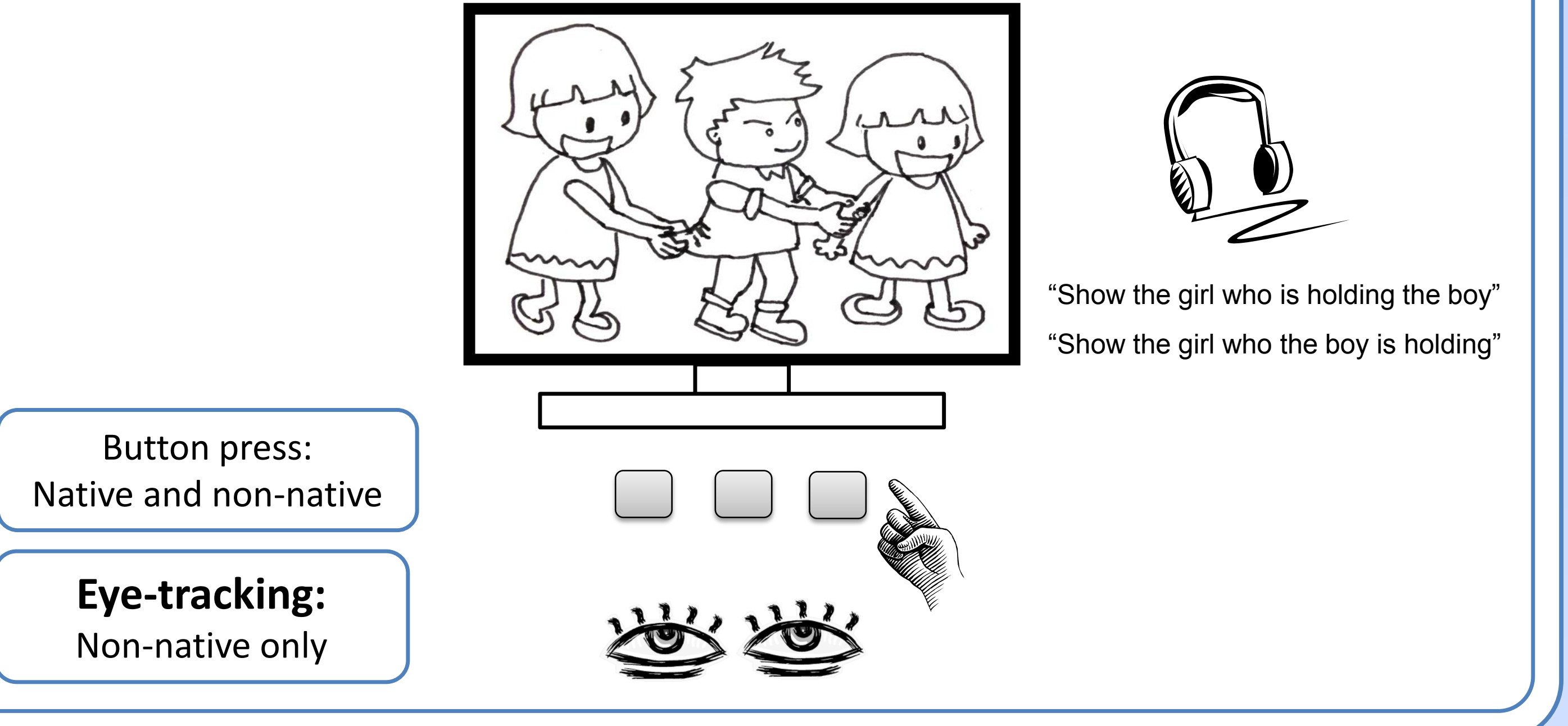

\section{Results}

Button press accuracy

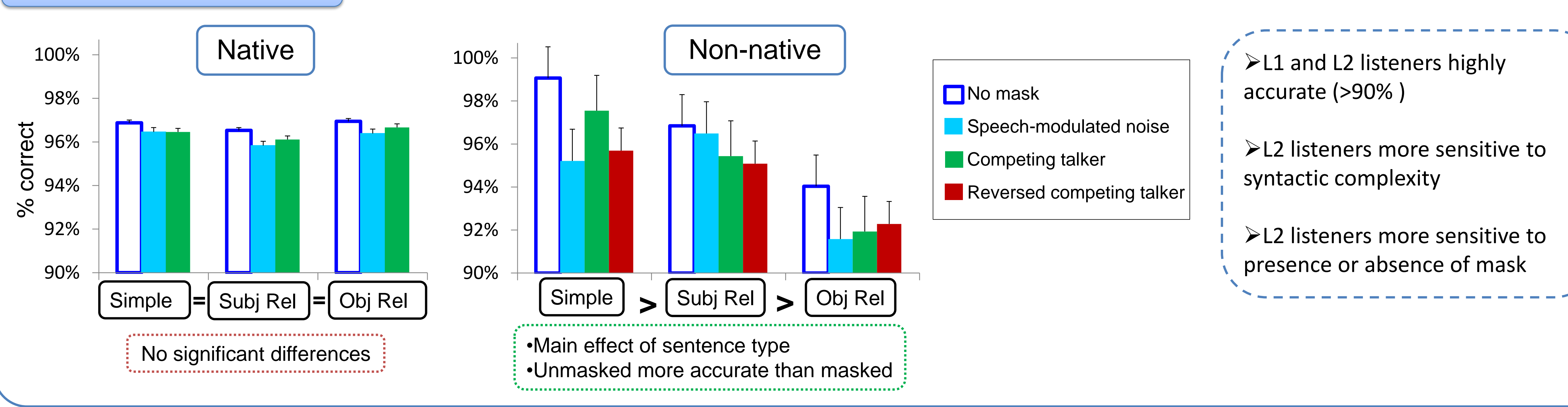

Button press reaction times

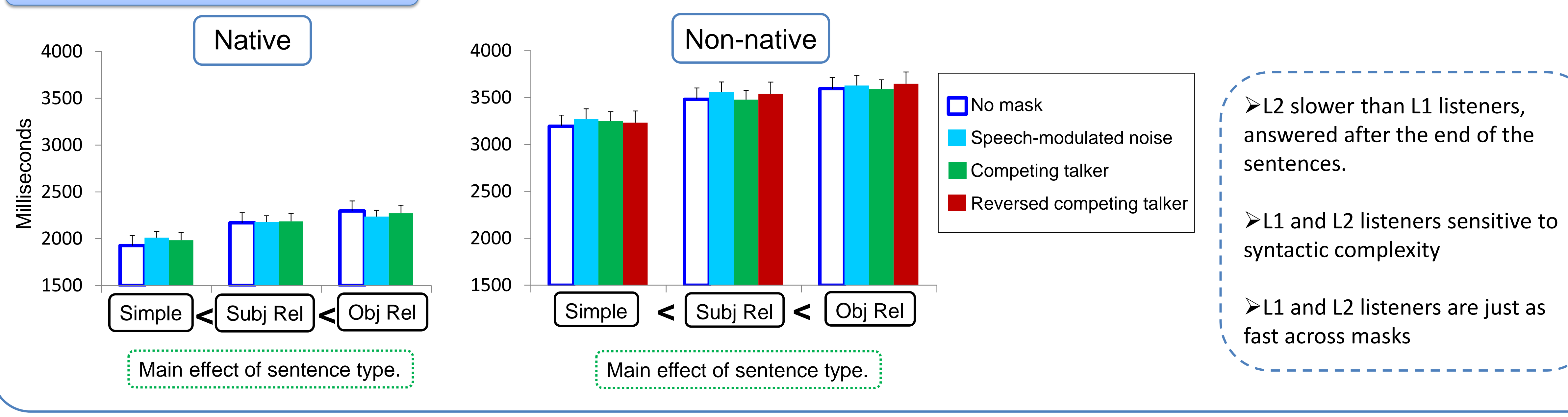

Eye-tracking (non-native only)
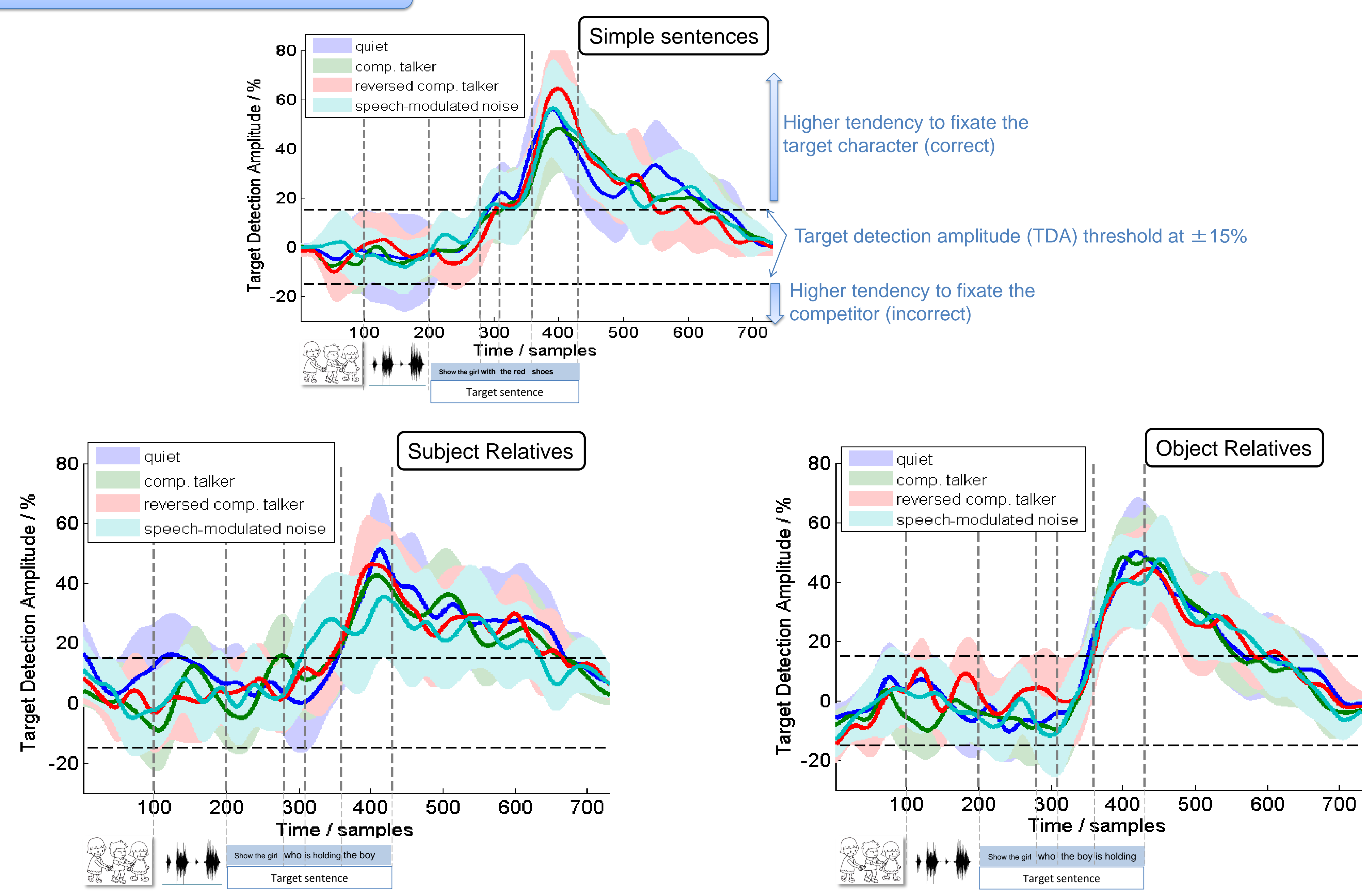

Eye-tracking allows to measure the online processes taking place before the button press for $\mathrm{L} 2$ listeners.

Participants tended to fixate the correct character (>15\%TDA) earlier for the simple sentences than for the relative clause sentences.

$>$ Regardless of the mask, or indeed whether the target was masked at all, participants fixated the correct character just as much in all conditions. $>$ This online measure confirms that even L2 listeners can be unperturbed by masking of speech.

\section{Conclusions}

A competing talker is not always more detrimental than energetic masking alone. In this task, listeners' processing was equally unperturbed across mas

2) The effect of syntactic complexity (Obj Rel vs Subj Rel) was replicated in all masked and unmasked conditions, both in native and non-native listeners.

3) Even when confronted with more complex syntax, native and non-native listeners' sentence processing was singularly robust to masking.

listeners' reaction times were slower across all conditions.

\section{References}

Brungart, D. S. et al. (2001). In
America, 10 (10), $2527-3$.

\section{Acknowledgments}

This project has received funding from the European Union's Seventh Framework Programme for research, technologica development and demonstration under grant agreement no FP7-PEOPLE-2011-290000. Thanks to Ling Ge for assistance in creating the visual stimuli for this experiment.

MARIE CURIE

